\title{
Specialized railway carriage for grain
}

\author{
Yadgor Ruzmetov ${ }^{*}$, and Dilmira Valieva \\ Tashkent State Transport University, Tashkent, Uzbekistan
}

\begin{abstract}
This article deals with the worked out specialized railway carriage for grain for the transportation process throughout the Republic of Uzbekistan railway network, with the unconditional provision of train traffic safety, which is one of the most important components of the rolling stock of railway transport.

The features of the load-bearing structure of the railway carriage for grain are that it is made based on a four-axle platform and a universal container. Evaluation of the strength of the metal structure of the grain car was carried out following the requirements of the "Standards for the calculation and design of new and modernized cars of the railways of the Ministry of Railways with a gauge of $1520 \mathrm{~mm}$ (non-self-propelled)".

Based on theoretical studies, it was justified that the design of a railway carriage for grain with a capacity of $83.6 \mathrm{~m} 3$ and a carrying capacity of 65 tons. For the first test of a railway carriage for grain, the number 43925684 was assigned.

The proposed new grain carriage will reduce operating costs and reduce rolling stock downtime during reloading operations. It will create the possibility of fulfilling contractual agreements drawn up for small volumes of traffic within the country.
\end{abstract}

\section{Introduction}

The unremitting functioning of the transportation process throughout the railway network of the Republic of Uzbekistan, with unconditional provision of train traffic safety, significantly depends on the serviceable car fleet, which is one of the most important components of the rolling stock of railway transport [1-3].

The balance of the freight car fleet of JSC "Uzbekistan Railways" for the period 20172025 , which for predicting period was determined based on the expected indicators of freight turnover and the volume of freight traffic by rail in the Republic of Uzbekistan, as well as taking into consideration the daily turnover of wagons, shows that the railways of Uzbekistan are currently experiencing a shortage of a working fleet of freight cars [4-7].

In view of the fact that the transportation process constantly requires a serviceable rolling stock, and the process of building freight cars is not able to meet the requirement fully for freight cars, work is underway to modernize cars at the enterprises of JSC " Uzbekistan Railways " [8-9].

\footnotetext{
*Corresponding author: yadgor.ruznmetov@yandex.ru
} 


\section{Materials and Methods}

Working out and valuation of the deformed condition of the body of a railway carriage for grain.

Meeting the requirement of local transportation of grain cargoes ordered by JSC " Uzbekistan Railways," it was developed the design documentation and manufactured a prototype of a grain carriage (Figure 1) by the specialists of the department "Cars and carriage facilities" of Tashkent State Transport University on the basis of CP "Uztemiryulmashtamir"

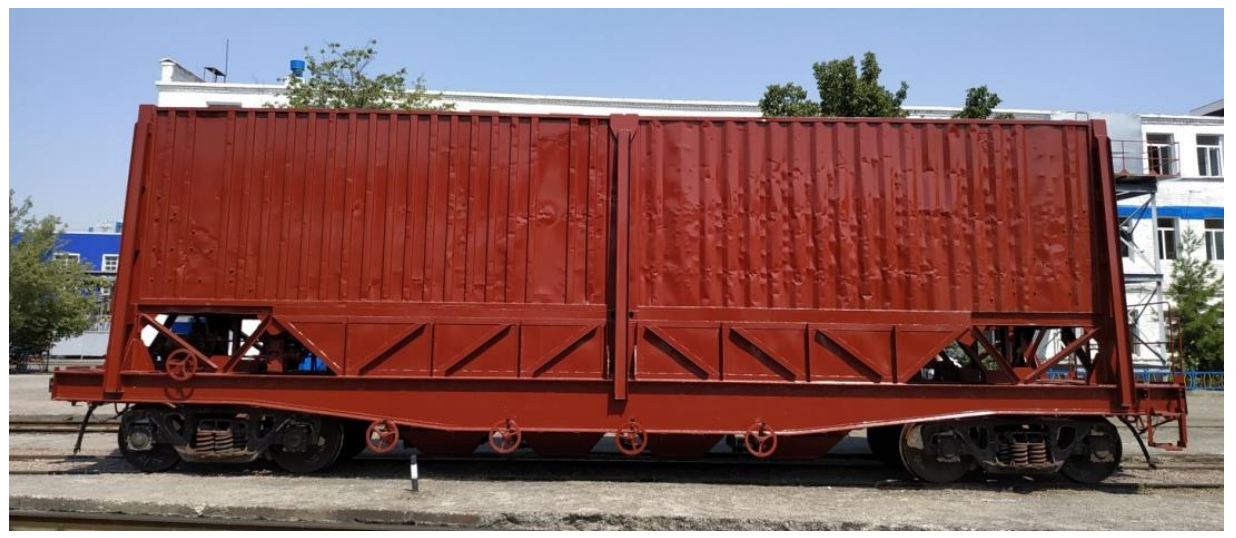

Fig.1. Railway carriage for grain worked out based on CP "Uztemiryulmashta'mir"

The features of the load-bearing structure of the railway carriage for grain is that it is made based on a four-axle platform and a universal container [10-11]. Evaluation of the strength of the metal structure of the grain car was carried out following the requirements of the "Standards for the calculation and design of new and modernized cars of the railways of the Ministry of Railways with a gauge of $1520 \mathrm{~mm}$ (non-self-propelled)" [12].

For theoretical studies, according to the valuation reformed strained condition of railway carriage's metal structure, it was worked out the computer model of a railway carriage for grain in the SolidWorks software environment (Figure 2, a). A computer model of a railway carriage for grain is a body with real inertial and geometric characteristics.

The structure of a railway carriage for grain has four upper loading hatches and eight unloading hatches and 4 steering wheels for seals and 1 mechanism for closing all the upper four hatches.
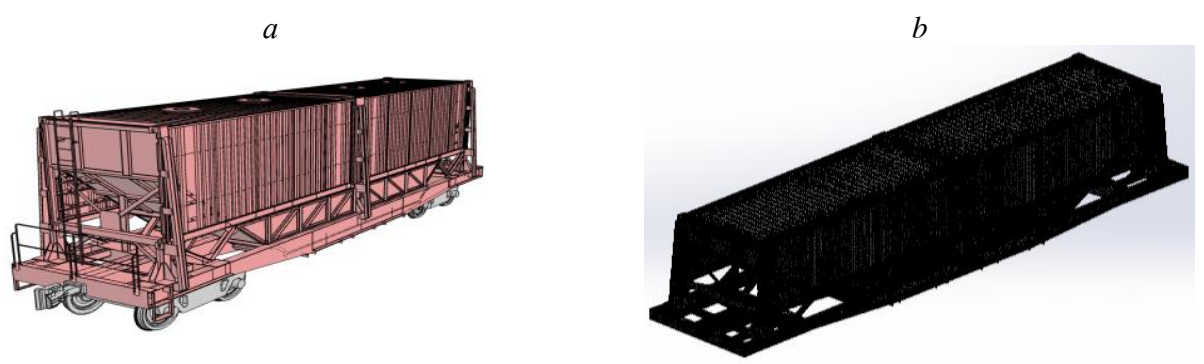

Fig. 2 Computer model (a) and finite element model (b) of the body structure of a railway carriage for grain 
Investigations of the strained deformed condition of the metal structure of a railway carriage for grain were carried out using the finite element method on the SolidWorks Simulation platform. The characteristics of the finite element grid of the computational model of a grain carriage (Figure 2, b) are presented in Tables 1 and 2.

Table 1. Grid Information (Table Fragment)

\begin{tabular}{|c|c|}
\hline Type of the grid & Solid mesh \\
\hline Using splitting: & Curvature-based mesh \\
\hline Jacobian points & 4 Points \\
\hline Maximum size of item & $100,788 \mathrm{~mm}$ \\
\hline Minimum size of element & $20,1575 \mathrm{~mm}$ \\
\hline Mesh quality plot & High \\
\hline
\end{tabular}

Table 2. Grid Information - Detailing (Table Fragment)

\begin{tabular}{|c|c|}
\hline Total nodes & 3686062 \\
\hline Total items & 1880037 \\
\hline Maximum aspect ratio & 57330 \\
\hline \% of elements with an aspect ratio $<3$ & 15,5 \\
\hline \% of elements with aspect ratio $>10$ & 28,7 \\
\hline \% distorted elements (Jacobian) & $5,32 \mathrm{e}-05$ \\
\hline
\end{tabular}

When modeling the dynamic characteristics of a railway carriage for grain, it was considered the options of the loaded and empty condition of the car, which is represented by the bulk. Kinematic and boundary conditions for loading the structure of a railway carriage for grain are shown in Figure 3.
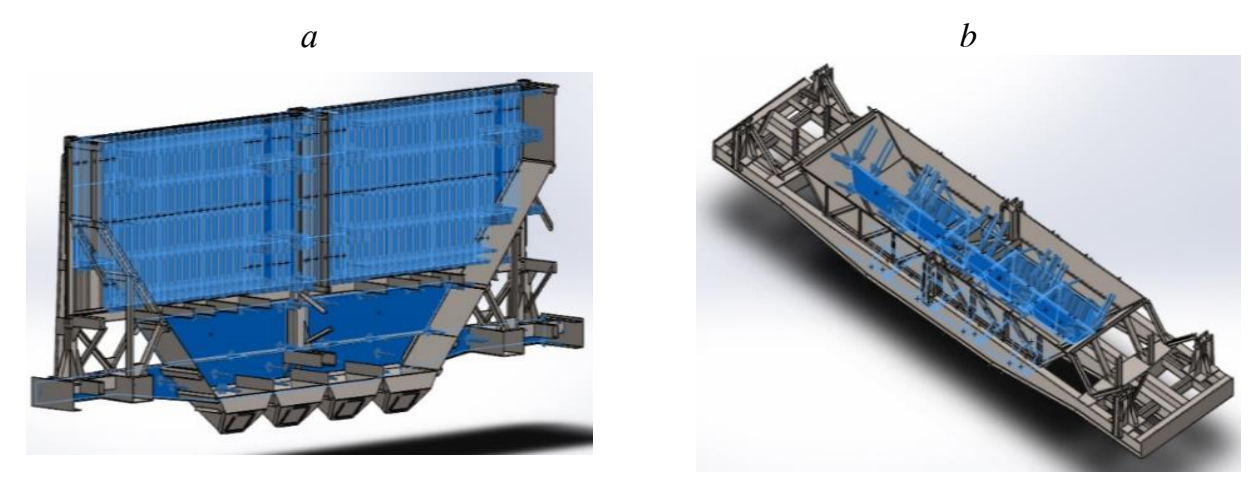

Fig. 3 Loading of the structure of a railway carriage for grain by the forces of grain cargo

As a result of calculations by the finite element method, the resulting distribution fields of strains and deformations by the structure of a railway carriage for grain are shown in Figure 4. 


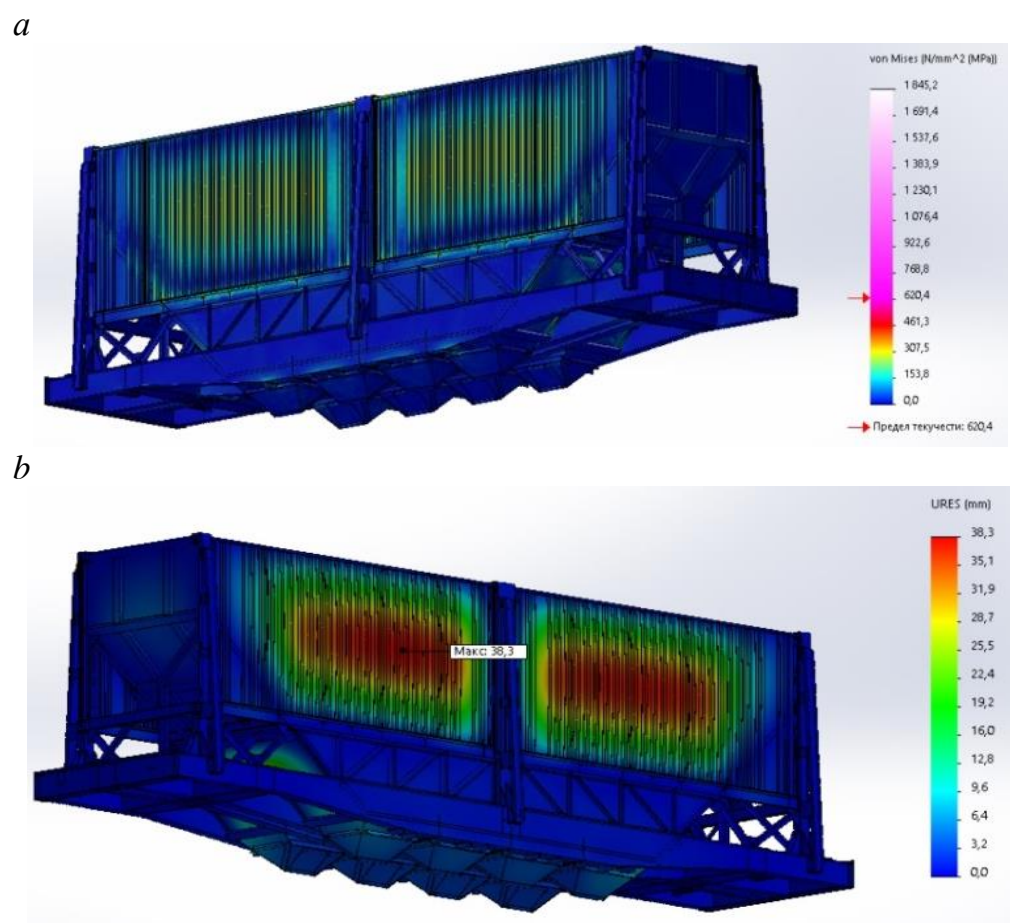

Fig.4 The results of the analysis of the strained reformed condition in accordance with the specified conditions: a are strains; $b$ is deformation

The analysis of the consistency of the computer model of a railway carriage for grain with the "Norm" [12] was carried out by comparing the calculated equivalent strain of railway carriage body with the permissible strains. The results of a comparative analysis of the data obtained during the calculation with the standard values showed that the worked out design of a railway carriage for grain meets the appropriate requirements.

Thus, on the basis of theoretical studies, it was justified that the design of a railway carriage for grain with a capacity of $83.6 \mathrm{~m} 3$ and a carrying capacity of 65 tons. For the first test of a railway carriage for grain, the number 43925684 was assigned. On both sides of a railway carriage for grain with a stencil "Experienced" was applied.

\section{Results and Discussion}

Production tests and verification of the reliability of the obtained research results

The first experimental loading of wheat was carried out at the grain elevator loading area adjacent to the Chinaz station. The railway carriage for grain with the number 43925684 was submitted for loading wheat on the access road of "Tashkent donmahsulotlari" JSC Chinoz branch (Figure 5, a). Before loading, a control reweighing of containers was carried out on wagon scales for 150 tons. In the process of reweighing the container of the car turned out to be 26.1 tons instead of the declared 26.3 tons. 

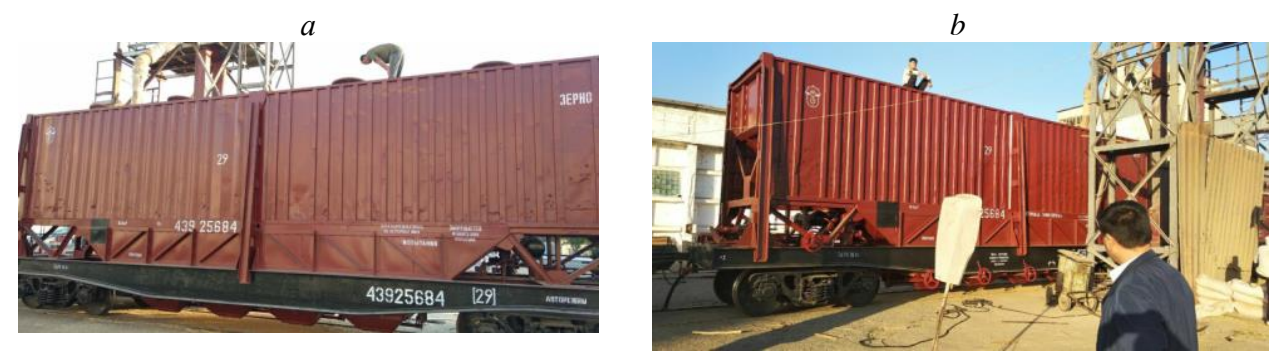

Fig. 5. Wheat loading test

After loading wheat, the upper loading hatches were checked for tightness of closure (Figure 5, b).

After loading the wheat it was carried out a control reweighing where $80900 \mathrm{~kg}$ were detected, a container was $26100 \mathrm{~kg}$, a transport batch of wheat was $54800 \mathrm{~kg}$. Five lead seals were placed on the shipper of the "Toshkent donmahsulotlari" Chinoz branch. During shunting operations from the lower unloading hatches of the grain carrier, no wheat scattering was found. After that, the cargo was accepted for transportation according to the road sheet № A574295 for its destination at the Tashkent-Tovarnaya railway station.

It was carried out the unloading at the grain elevator unloading area adjacent to the Tashkent-Tovarnaya station. The grain car with the number 43925684 according to the road sheet number A574295 was delivered for unloading wheat to the access road of JSC "Toshkent donmahsulotlari" (Figure 6).

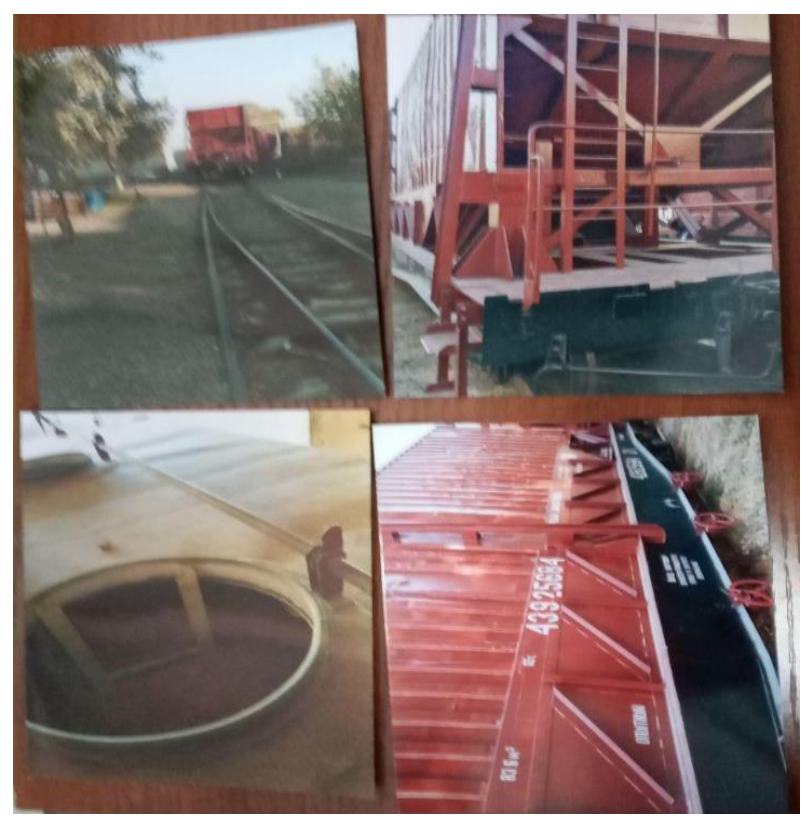

Fig. 6. Wheat unloading test

Before unloading, a control reweighing of containers was carried out on wagon scales at JSC "Toshkent donmahsulotlari", where 80,880 kg were detected. After unloading the wheat, the car was reweighed, at which the container of the grain car was $26100 \mathrm{~kg}$. Total transport consignment of wheat $54,780 \mathrm{~kg}$. Experimental transportation of grain cargo in a 
grain carriage was carried out three more tests between the stations Chinaz - TashkentTovarnaya.

\section{Conclusion}

Thus, based on theoretical studies and tests, a new design of a grain carriage with a capacity of $83.6 \mathrm{~m} 3$ and a carrying capacity of 65 tons was justified. The proposed new grain carriage will reduce operating costs and reduce rolling stock downtime during reloading operations. It will create the possibility of fulfilling contractual agreements drawn up for small traffic volumes within the country.

\section{Acknowledgements}

The authors express their deep gratitude to the management by JSC "Uzbekistan Railways" and CP "Uztemiryulmashtamir" for all third-party assistance in implementing research work on testing a sintered grain carriage.

\section{References}

1. Rahimov R.V, Analysis of the state and prospects of the development of the freight wagon fleet of the Republic of Uzbekistan, R.V. Rahimov, Ya.O. Ruzmetov, NonFerrous Metals. 44. (1). pp 7-11 (DOI: 10.17580,nfm.2018.01.02). (2018).

2. Rasulov M.Kh, Problems of increasing the competitiveness of local railway corridors , M.Kh. Rasulov, U. N. Ibragimov, R.V, Rakhimov, Scientific works of the Republican scientific and technical conference with the participation of foreign scientists "Resource-saving technologies in railway transport". - Tashkent: TashIIT, p. 14 - 17. (2013)

3. Rakhimov R.V, Choice of directions for the development of the wagon fleet of Uzbekistan railways, R.V. Rakhimov, Transport of the Russian Federation. 1 (74). pp. 71 - 74. (2018).

4. Rakhimov R.V, State and prospects for the development of the wagon fleet of railways in Uzbekistan, R.V. Rakhimov, Materials of the XIII International Scientific and Technical Conference "Rolling stock of the XXI century: ideas, requirements, projects". - SPb .: FGBOU VO PGUPS, pp. 124 - 128. (2018).

5. Ruzmetov Ya.O, Prospects for the development of car building in the Republic of Uzbekistan, Ya.O. Ruzmetov, R.V. Rakhimov, Collection of scientific works of the VIII All-Russian scientific-practical conference "Problems and prospects for the development of carriage building." - Bryansk: BSTU, pp. 147 - 150. (2019).

6. Rakhimov R.V, Analysis of the state and development prospects of the freight car fleet of JSC "Uzbekiston temir yullari" , R.V. Rakhimov, Scientific works of the Republican scientific and technical conference with the participation of foreign scientists "Resource-saving technologies in railway transport". - Tashkent: TashIIT, pp. 91 - 94. (2017).

7. Rakhimov R.V, Uzbekistan railways, Wagon parks of AJ: present condition and prospects, R.V. Rakhimov, D.N. Zairova, Bulletin of Tashkent State Technical University. 2 (103). pp. 136 - 142. (2017).

8. Rakhimov R.V, Modernization of a tank car for transportation of concentrated sulfuric acid, R.V. Rakhimov, Ya.O. Ruzmetov, Scientific works of the Republican scientific and technical conference with the participation of foreign scientists 
"Resource-saving technologies in railway transport". - Tashkent: TashIIT,. pp. 46 - 49. (2016).

9. Rahimov R.V, Development of maintenance and repairing tank wagon for the transport of concentrated sulfuric acid, R.V. Rahimov, Ya.O. Ruzmetov, Bulletin of Tashkent State Technical University. (2). pp. 86 - 91. (2017).

10. Ibragimov N.N, Research of design and operating conditions of containers for fruit and vegetables, N.N. Ibragimov, R.V. Rahimov, M.A. Khadjimukhametova , Proceedings VIII International Scientific Conference "Transport Problems 2016". Katowice: Silesian University of Technology Faculty of Transport,. pp 174 - 181. (2016).

11. Rakhimov R.V, Development of design and operating conditions of containers for transportation of fruits and vegetables, R.V. Rakhimov, M.A. Khadzhimukhametova , Bulletin of Transport of the Volga Region. 2 (56). pp. 75 - 81. (2016).

12. Standards for the calculation and design of new and modernized railcars of the railways of the Ministry of Railways with a gauge of $1520 \mathrm{~mm}$ (non-self-propelled). M .: GosNIIV-VNIIZhT, p 317. (1996) 